\title{
Ensinar e aprender a ensinar HistórIa
}

\author{
Thiago Fernando Sant' Anna* \\ tfsantanna@yahoo.com.br
}

\begin{abstract}
Resumo: No presente artigo, objetivei descrever minhas experiências como docente em Didática e Prática de Ensino em História e Estágio Supervisionado em História na Universidade Federal de Goiás e Universidade Católica de Goiás. Para tal, discorri sobre as propostas da historiografia do ensino de História nos últimos anos, como a distância entre Universidade e Escola, a produção de conhecimento, o livro didático, o eixo temático e o uso de diferentes linguagens no ensino de História. Por último, apontei quatro eixos norteadores do ensino de história como a problematização, os conceitos históricos, a relação entre o passado e o presente e as habilidades dos/as alunos/as a serem desenvolvidas.
\end{abstract}

Palavras-Chave: História, Ensino, Didática.

DENUNCIANDO PRECONCEITOS, APONTANDO CAMINHOS...

Minha experiência profissional com as disciplinas "Didática e Prática de Ensino em História” e "Estágio Supervisionado", no curso de História das instituições Universidade Federal de Goiás e Universidade Católica de Goiás, durante o ano de 2006-2007, bem como o contato com obras a respeito do assunto, permitiu-me fazer algumas considerações sobre a condução do programa de estágio na área. Neste artigo pretendo discorrer sobre tal experiência e apontar perspectivas para a prática de ensinar a ensinar História.

Não há como deixar de ressaltar que algumas experiências de campo contribuíram largamente para elaboração das minhas considerações sobre ensino de História. Dentre elas, apontaria o contato com duas realidades distintas: uma, "de ponta", que é a sub-área de História do Centro de Ensino e Pesquisa Aplicada à Educação ${ }^{1}$, da Universidade Federal de Goiás

* Professor da UEG-Campus Cora Coralina. 
(CEPAE/UFG); a outra, nua e crua, que é a realidade das escolas públicas da rede estadual e municipal de Goiânia, carentes de condições materiais devido ao sucateamento acumulado pelo descaso das autoridades para com a educação goiana ${ }^{2}$.

Tais experiências permitiram-me perceber que entre coordenadores, discentes e professores, as práticas construídas no decorrer da realização dos trabalhos profissionais e intelectuais voltados para a didática foram interpeladas pelas representações depreciativas vigentes sobre o ensino em História. Estas representações, reforçadas pela própria comunidade acadêmica, foram apontadas pelo professor Leandro Karnal, quando da sua vinda a Goiânia para ministrar conferência. Segundo Karnal, difunde-se nos corredores da academia, a ideia de que ensinar é menos do que pesquisar, de que o ensino não é bem visto frente à pesquisa, de que quem somente ensina conhece menos do que quem pesquisa ${ }^{3}$. Isso, para Leandro Karnal, não deixa de ser uma contradição, pois o ensino é mais reconhecido financeiramente do que a pesquisa. Egressos/as dos cursos de História se tornam professores/as e, pouquíssimos/as, pesquisadores/as. Trata-se, sem dúvida, de um curso de formação de professores/as de história. ${ }^{4}$

Foi nesse campo, às vezes minado, que procurei construir esta experiência em estágio. Propus um plano de curso que, ao lançar mão da discussão historiográfica do ensino de História e dos Parâmetros Curriculares Nacionais, de certa forma, pudesse nortear-nos na condução da disciplina de "Didática e Prática de Ensino em História" e "Estágio Supervisionado", em meio a tais representações sobre o ensino e a pesquisa. É a respeito de tal experiência que gostaria de tecer alguns comentários.

De forma geral, o caminho passou pelo uso de uma historiografia do ensino de História, pela análise crítica da legislação (Parâmetros Curriculares Nacionais, Lei de Diretrizes e Bases, Diretrizes Curriculares Nacionais para Área de História), pela prática de estágio construída com base na relação entre ensino, pesquisa e extensão, e pelo desenvolvimento de projetos pedagógicos nas escolas-campo e relatórios finais.

O incentivo à leitura de textos sobre o ensino de História, o estímulo à pesquisa na área, a elaboração de projetos pedagógicos, bem como o "retorno" dado às escolas em forma de projetos de intervenção, foram propostas adotadas nos programas das disciplinas acima citadas. De alguma forma, a proposta procurava articular, durante o ano letivo, na realização do tripé ensino-pesquisa-extensão, experiências dos/as alunos/as estagiários/as não somente voltadas para as condições iniciais da formação docente, mas também para a formação de pesquisadores/as em ensino de história. 
PERSPECTIVAS HISTORIOGRÁFICAS: UNIVERSIDADE/ ESCOLA, LIVRO DIDÁTICO, EIXO TEMÁTICO, LINGUAGENS

A historiografia sobre ensino de história tem repensado a formação de professores e professoras na área da História, nos últimos 30 anos, junto às mudanças nas políticas educacionais e às transformações no âmbito do conhecimento histórico. Daí, as noções como História-Problema, Verdade Relativa, a pluralidade de sujeitos históricos bem como outras advindas das novas correntes historiográficas (Nova História Francesa e História Social Inglesa) têm sido incorporadas e pensadas dentro da historiografia sobre o ensino de História.

Para apontar as inquietações fundamentais dessa historiografia, gostaria de retomar aqui um texto de Selva Guimarães Fonseca a respeito de quatro preocupações discutidas nos textos sobre ensino de história: a distância entre Universidade e Escola, o livro didático, o ensino temático e o uso de novas linguagens no ensino de história. Para a autora:

Vivenciamos, nos últimos anos, um processo de revisão dos esquemas globalizantes, homogeneizantes, que durante muitos anos nortearam as práticas historiográficas; uma ampliação do campo da história, através de uma busca de novos objetos e de novos documentos. Por outro lado, tivemos de nos defrontar com uma política de descaracterização e desvalorização da história no $1^{\circ}$. e $2^{\circ}$. graus, através de uma série de medidas governamentais, explícitas na Lei 5.692/71.

A partir deste contexto, multiplicaram-se as discussões acerca do conhecimento Histórico, abrindo um diálogo entre espaços e formas de produção, através de trocas de experiências cada vez mais constantes.

A natureza dessas discussões, expressas em diferentes obras, hoje divulgadas em todo o país, possibilita apreender múltiplas perspectivas que vêm constituindo/reconstituindo as dimensões do ensino de História entre nós. (FONSECA, 1990, p. 197-198)

Autoras como Déa Fenelon, Elza Nadai, Marcos Silva, Circe Bittencourt, Conceição Cabrini e outras ressaltaram aspectos relativos à distância entre Universidade e Escola. ${ }^{5}$ Nessas pesquisas, realizadas dos anos 70 aos 90 do século XX, concluiu-se que existia uma distância/discrepância entre as práticas e os saberes históricos produzidos, debatidos e transmitidos nas universidades e aqueles ensinados e aprendidos nas escolas de ensino fundamental e médio. 
De um lado, nos cursos superiores, os temas eram objetos de várias leituras e interpretações, predominando uma diversificação de abordagens, problemas e fontes. De outro lado, nas escolas de ensino fundamental e médio, de uma maneira geral, as práticas conduziam à transmissão "da História", como uma versão que se impunha como "a" verdade. A formação universitária constituía o espaço da diversificação, do debate, do confronto de fontes e interpretações. A formação escolar, o lugar da transmissão, da voz uníssona do/a professor/a, do livro didático eram a única fonte disponível (FONSECA, 1990, p. 197-208).

Em outro momento, a autora assinala as condições históricas que levaram a essa situação. Segundo Fonseca,

essa configuração é fruto do modelo de formação inicial de professores de história e geografia, realizado nos cursos de licenciatura curta de estudos sociais, instituídos no Brasil durante a ditadura militar, no interior do projeto de descaracterização das humanidades no currículo escolar e de (des)qualificação dos professores de história. Trata-se de um projeto de desqualificação estratégica, articulada a diversos mecanismos de controle e manipulação ideológica que vigoraram no Brasil no período do regime militar. (FONSECA, 2004, p. 61)

Dessa forma, a mudança dessa política educacional instalada desde a Ditadura Militar, voltada sobretudo para reduzir a distância entre Universidade e Escola, passa por estabelecer, na atualidade, uma outra relação com o conhecimento histórico nas escolas. Ou seja, isso implica agora enfocar a produção do conhecimento histórico dentro das escolas, de forma a romper com o papel de reprodução que tradicionalmente é conferido ao ensino fundamental e médio. Fonseca havia levantado algumas problematizações a respeito em sua tese de doutorado, "Caminhos da História Ensinada", publicada pela primeira vez em 1993:

é possível produzir conhecimento na escola de $1^{\circ}$. Grau sem que isso signifique perda na transmissão e recepção de informações? É possível garantir um "patamar mínimo" de transmissão de informações? A escola fundamental produzindo conhecimento não estaria abaixando o nível do ensino? É papel da escola fundamental produzir ou reproduzir o conhecimento? (FONSECA, 1993, p. 125)

Diminuir a distância entre Universidade e Escola, reconhecer a possibilidade de produção do conhecimento histórico por alunos/as dos 
ensinos fundamental e médio nos termos apontados por Fonseca (1990, p. 199), implica incorporar perspectivas de ensino voltadas para a reflexão da História. Segundo a mesma autora:

O objetivo central da proposta é conseguir que alunos realizem, a partir de elementos levantados para o exame de uma determinada realidade histórica, algum trabalho de reflexão que os leve à produção de conhecimento sobre esta realidade e à compreensão da forma como este conhecimento foi construído. (FONSECA, 1990, p. 199)

Outro aspecto ressaltado pela historiografia de ensino de História diz respeito ao livro didático. As reflexões pautam-se no significado da utilização dele e na análise dos conteúdos por ele veiculados. Normalmente, apesar das conquistas sobre democratização, o livro didático traz um "conhecimento impositivo". Ele impõe fatos e explicações, impõe uma forma e uma linguagem para se estudar história e impõe também um conjunto de documentos importantes para a História. Nesse sentido, o livro didático, tomado como objeto privilegiado na condução do ensino de história, pode ser um grande obstáculo às perspectivas de pesquisa em sala de aula, implementadas por professores/as e alunos/as. ${ }^{6}$

Ao depararmo-nos com realidades em salas de aulas de escolas públicas onde professores/as apenas repetem o que os livros didáticos afirmam, a conclusão óbvia a que se chega é a de que o livro didático é mal utilizado. Isso porque ele retira dos docentes a possibilidade de pensar sobre interpretações, refletir e ter uma postura crítica em relação ao conhecimento histórico.

O livro didático utilizado como "o" saber esmaga a emergência dos outros "saberes" veiculados na sala de aula como o conhecimento prévio dos alunos e as experiências dos professores ${ }^{7}$, além de inviabilizar o uso de outras versões da história. Tal processo de silenciamento de saberes e versões se intensifica com a incorporação do livro didático pela indústria cultural, ou seja, ele é submetido às leis de mercado, às exigências das editoras e aos interesses das ideologias dominantes. É também transformado em objeto de culto e desejo mercadológico por minar as exigências pedagógicas e sociais. ${ }^{8}$

Em face desta situação do livro didático, Fonseca aponta duas correntes. A primeira defende a completa substituição do livro didático por outros materiais. Expulso da sala de aula nos ensinos fundamental e médio, o vazio deixado pelo livro didático seria preenchido pelo trabalho de pesquisa por professores/as e alunos/as em outros documentos. O material didático seria montado a partir de textos didáticos, jornais, mapas, revistas, 
fotografias, documentos históricos, entrevistas, enciclopédias etc. A segunda corrente, menos radical que a primeira, defende um trabalho crítico com o livro didático, no qual professores/as, ora complementam, ora contrapõem a leitura do livro didático com a de outras fontes. Nessa perspectiva, o livro didático não seria "a" fonte privilegiada e nem deixaria totalmente de sê-la, mas passaria a ser "uma" das fontes. ${ }^{9}$

Uma terceira abordagem da historiografia, subsidiada com ênfase pelas propostas dos Parâmetros Curriculares Nacionais, incorpora o principal debate teórico-metodológico da ciência da história depois da Crise dos Paradigmas: História Total X Micro História, ou História Global X História Geral, conforme Michel Foucault (2000, p. 11-12). Fundamentada na perspectiva de que não se pode apreender a totalidade do social, a proposta de uma história temática defende o recorte em torno de temas como pontapé inicial para qualquer incursão pela pesquisa e pelo ensino de história.

De acordo com os Parâmetros Curriculares, os eixos temáticos fundamenta-se no recorte de qualquer tema ou objeto com vias a apreender a totalidade do social, pois a totalidade não é sinônimo de visão global. No documento do Ministério da Educação, tais eixos são contemplados na reunião das séries em ciclos da seguinte forma: no terceiro ciclo ( $5^{\mathrm{a}}$. e $6^{\mathrm{a}}$. séries) estuda-se a História das relações sociais, da cultura e do trabalho, atentando para as noções de relações sociais, a relação do homem com a natureza e com a terra e as relações de trabalho; no quarto ciclo $\left(7^{\mathrm{a}}\right.$. e $8^{\mathrm{a}}$. séries) estuda-se a História das representações e das relações de poder, com atenção aos conceitos de nação, povo, guerras e revoluções, além de outras como cidadania e cultura no mundo contemporâneo. ${ }^{10}$

Segundo Fonseca (1993, p. 106), a característica principal da proposta temática é que,

ao deixar impor um quadro geral com a evolução da história da sociedade, ela traz elementos para o professor incorporar no ensino de história outros objetos, outros documentos e problemáticas que até então estiveram restritas ao trabalho acadêmico especializado ou que sequer foram investigadas.

Percorrer essa proposta temática permite-nos partir do tema recortado em direção aos sentidos dados aos objetos em diferentes contextos históricos, como as noções de trabalho, cidadania, relações de poder etc.. Trabalha-se aqui com noção de que a historicidade dos objetos capta sentidos imprimidos aos textos, a ponto de não tomá-los como determinados por um contexto 
dado, pré-estabelecido. ${ }^{11}$ Assim, o contexto a priori não explica o fato, mas é o discurso sobre o fato que nos permite compreender o contexto produzido a posteriori. Não é a Idade Média que explica as relações de trabalho entre senhores e servos, mas são essas relações de trabalho baseadas no contrato da servidão que nos permitem compreender apenas alguns aspectos da Idade Média.

Um dos principais receios em relação ao ensino temático como proposta alternativa ao ensino de História tradicional é que o trabalho com objetos específicos pode levar a perder a "totalidade do social", pulverizar-se e esgotar-se no tema. Ora, isso não é um problema! Como se fosse inviável qualquer crítica à história total/totalizante. Mas se trata de um caminho pelo qual é possível ensinar a partir uma história temática e romper com "a" história total. Tornaria possível também questionar, no ensino de História nas séries fundamentais e médias, a possibilidade de apreender todo o contexto histórico e os fatos, como por exemplo, da Idade Média. Nesse sentido, enveredaríamos apenas pelos discursos que circularam na História, como nos tempos chamados medievais.

Apesar da proposta inovadora, observei uma prática no ensino de história comum entre professores/as que buscaram incorporar a história temática dos Parâmetros, quando, na maioria das vezes, não ensinava dentro da arcaica História tradicional. Trata-se de usar a proposta de história temática "dentro" do esquema tradicional. Quero dizer com isso que a prática de ensino se limitava a estabelecer o tema dentro de um contexto construído pela história total ou totalizante. Assim, por exemplo, ensinava-se sobre as mulheres na Idade Média (dentro do tema "História das Relações de Trabalho") depois de ter se estudado o contexto social, econômico e político medieval. Não possibilitava assim problematizar as diversas percepções e contradições vivenciadas pelos diferentes sujeitos. O que poderia ser um instrumento de mudança nas práticas de ensino de história perdia seu caráter subversivo e transformador para ser domesticado dentro do modelo tradicional.

Ora, acolher as propostas de mudança da história temática no ensino de História implicaria romper com esse contexto dado, pré-discursivo. Nessa perspectiva, não seria conduzido o estudo das formas de trabalho das mulheres na Idade Média como se fosse um efeito do contexto sócio-econômicopolítico, mas como alguns discursos medievais - a pintura, o romance de cavalaria - representaram os trabalhos das mulheres naquela sociedade.

Por último, a preocupação historiográfica assinalada por Fonseca vai ao encontro do uso das novas linguagens no ensino de história. Tais procedimentos incorporam experiências a partir do uso de diferentes linguagens e 
recursos no ensino de História nos ensinos médio e fundamental como música, literatura, filmes, TV, histórias em quadrinhos, documentos. O objetivo de se trabalhar com tais linguagens é confrontar a linguagem única e "oficial" do livro didático e criar condições para que os alunos possam desenvolver outras habilidades como a análise de imagens, de letras de música, etc. ${ }^{12}$

Debater as propostas da historiografia revelou-se experiência profícua na condução da disciplina de Didática e Estágio. O próximo passo foi partir para a produção de planos de aula e para as regências de aulas nas escolas campo.

Diga-me COMO PLANejas, QUE TE diREI COMO ENSINAS!

Simultâneo ao trabalho de leitura da historiografia do ensino de história, a parte prática da disciplina consistia na elaboração de planos de aula para subsidiar as regências de aulas no estágio. Todo plano e regência de aula deveriam conter um tema, um conjunto de objetivos geral e específicos, uma metodologia, atividades e uma bibliografia composta de livros didáticos, paradidáticos e universitários.

Surgiram então nossos primeiros problemas: a ênfase teórica, durante todo o curso de História que despreza a prática de sala de aula, deixou os/as alunos/as inseguros/as quanto a qualquer atividade ligada à prática. Outro debate interessante veio dos/as alunos/as que já possuíam experiência em sala de aula, que já foram e, que no momento, eram professores/as e criticavam a elaboração de planos de aula. Faziam isso com base no argumento de que o excesso de atividades ligadas à prática docente e os parcos salários obstaculizam a elaboração de planos de aula. O plano era, então, visto como produção desnecessária uma vez que nenhum/a professor/a o elaborava.

Ao final desses debates, chegamos à conclusão de que, mesmo considerando as limitações do plano - a de que professores/as têm certa resistência em elaborar um a um por aula, a de que o plano tem uma função clara de permitir que a coordenação controlasse/supervisionasse as aulas de história e, por último, a de que o plano de aula sempre sofre alterações no decorrer das aulas - ele era necessário. Primeiro porque, em consonância com José Carlos Libâneo (1994, p. 223), o planejamento permite-nos controlar/orientar nossas aulas, servindo para alunos/as que teriam suas primeiras experiências em sala de aula como um forte componente de segurança; segundo, porque o plano de aula possibilita que professores/as de história tenham um controle sobre seu discurso de ensino de história, ao compreender suas concepções de ensino, avaliar e compor uma experiência na educação. 
Para a elaborar os planos de aula e exercer as regências nas escolascampo eram fundamentais a compreensão e a incorporação de quatro eixos principais. São eles: a problematização, os conceitos, a relação entre o passado e o presente e as habilidades dos alunos das escolas campo a serem desenvolvidas. Esses eixos norteadores seriam responsáveis por criar condições favoráveis nas aulas no encontro entre a proposta prática e as novas perspectivas de ensino de história assinaladas pela historiografia do ensino de história.

A problematização implica pensar que os estagiários não podem reduzir a abordagem do conhecimento histórico à mera descrição e repetição de eventos. Não que isso fosse totalmente desnecessário. Propomos romper com a percepção de que na aula de história o professor expõe o conteúdo e os alunos, de forma passiva, o recebem como se fosse informação/verdade (BITTENCOURT, 2004, p. 226-230). Essa forma de perceber o ensino acabava por alimentar os egos docentes que enxergam na aula expositiva o melhor caminho para o aprendizado - o do próprio docente. Portanto, longe de palestrar para alunos/as, os/as estagiários/as deveriam construir condições para problematizar o conhecimento histórico, abordá-lo de forma questionadora, indagá-lo e não aceitá-lo como verdade última.

Ora, surge daí um primeiro problema: como problematizar/criticar sem ter repertório? Como debater o tema sem ter conteúdo? Retomemos a pergunta lançada por Selva Fonseca: "é possível produzir conhecimento na escola de $1^{\circ}$. Grau sem que isso signifique perda na transmissão e recepção de informações?" Isso requer dos alunos estagiários a preparação inicial para conseguir ensinar de forma problematizada, pois a História, mesmo a ensinada, deve partir de problemas do presente, das representações presentes nos documentos/livros e demais materiais didáticos, dos conteúdos já trabalhados e do conhecimento prévio dos alunos.

A capacidade para problematizar e trabalhar com a perspectiva de uma história temática, bem como saber ensinar para além do livro didático requer embrenhar-se pela análise de documentos em sala de aula. É comum atribuir-se à análise de documento o trabalho de estudante de graduação e pós-graduação. Dessa forma, durante a aula de história no ensino fundamental e médio, os estudantes apreendem uma história descritiva e os principais fatos da história. E somente durante um curso de graduação e pós-graduação, os/as alunos/as fazem análise de documento e produzem conhecimento. ${ }^{13}$

Um segundo eixo da prática de ensino de história se refere aos conceitos a serem trabalhados nas aulas de história. Não se ensina história somente pela 
descrição de fatos, como se apenas contasse uma história. Mas, além de problematizar a história contada, é necessário abordar as narrativas a partir de alguns conceitos, ou melhor, criar condições para que alunos e alunas de ensino fundamental e médio possam mobilizar conceitos para interpretar fatos históricos.

Segundo Holien Bezerra (2004, p. 41), alguns conceitos formam o arcabouço da prática dos historiadores, constituindo-se uma determinada "lógica da História", concebida como "um conjunto de procedimentos e conceitos em torno dos quais devem girar as preocupações dos historiadores". Para este autor, o que diferencia as diversas concepções de História "é a forma como esses conceitos e procedimentos são entendidos e trabalhados" (Bezerra, 2004: 41). História, processo histórico, tempo, sujeito histórico, cultura e cidadania são alguns dos conceitos principais a serem destacados nas aulas de história.

Como outros exemplos, podemos dizer que para estudar a transição do trabalho escravo para o trabalho assalariado no Brasil é fundamental discutir com os alunos o que significam estes termos - trabalho livre e escravo; para estudar as representações do feminino nas obras de arte grega seria possível fazer isso por meio da noção de gênero; e para estudar o surgimento do movimento operário poderia fazê-lo pelo estudo dos conceitos de socialismo, capitalismo, anarquismo etc.

Abordar conceitos é sempre viável e útil, desde que tenham sua historicidade reconhecida. Como noções criadas para compreender as diversas realidades históricas, seus significados, os conceitos podem tanto ser "abrangentes" ou se referir a realidades determinadas. Segundo Bezerra, são categorias "em aberto", "vetores à espera de concretizações com base na elaboração de conhecimentos específicos, de acordo com os procedimentos próprios da disciplina História" (BEZERRA, 2004, p. 47).

Um terceiro eixo na prática de ensino de história refere-se à relação passado-presente, o qual está vinculado aos outros, sobretudo, à problematização, pois a apreensão e a problematização do passado não devem ser feitas prescindindo dos problemas do presente. O historiador, assim como o estudante da disciplina da história nos níveis fundamental e médio, deve sempre partir das inquietações do seu presente, das suas experiências de vida para encarar os fatos do passado.

Já dizia Croce que toda história é história contemporânea. O/a historiador/a deve, portanto, partir das indagações do presente para analisar/interpretar o passado. Ensinar, por exemplo, a democracia ateniense da Antiguidade pode ser possível fazendo uma relação com a democracia contemporânea. Da mesma forma, falar sobre a alienação do trabalhador 
nas empresas atuais pode ser um passo inicial frutífero para compreender o fordismo e a realidade do proletariado do início do século XX. Adensando mais sobre a percepção do presente pelos alunos, poderíamos falar do matrimônio nos tempos passados, utilizando fotografias de casamento de familiares dos alunos na atualidade.

Assim, o/a professor/a de história precisa saber administrar a mobilização de saberes em sala de aula, como o saber da sua experiência na profissão, o saber do livro didático (que traz uma história pronta a ser ensinada) e o saber dos/as alunos/as que carregam formas de conhecimentos advindas das suas experiências de vida. ${ }^{14}$ No que se refere a este saber dos/as alunos/as, Circe Bittencourt, elucida o uso do conceito de representações sociais no ensino de história. Por representações sociais, entendemos as acepções de Moscovici e Jodelet, respectivamente:

constituem um corpo organizado de conhecimentos bem como uma das atividades psíquicas pelas quais os homens tornam a realidade física e social inteligível, inserem-se em um grupo ou estabelecem uma relação cotidiana de trocas e comunicação. (MOSCOVICI apud BITTENCOURT, 2004, p. 236) é uma forma de conhecimento, socialmente elaborada e partilhada, com um objetivo prático, e que contribui para a construção de uma realidade comum a um conjunto social. Igualmente designada como saber de senso comum ou ainda ingênuo, natural, esta forma de conhecimento é diferenciada, entre outras, do conhecimento científico. (JODELET, 2001, p. 22)

Apropriando-se desse conceito de representações sociais para o ensino de história, podemos afirmar que ensinar é trazer para o debate em sala de aula o conhecimento prévio, o conhecimento construído no cotidiano, as noções do senso comum, as experiências de vida que os/as alunos/as, na sua pluralidade, vivenciam na realidade.

Contudo, cabe reforçar o papel do docente nesse processo, ou seja, como o professor deve conduzir o aluno à apreensão do conhecimento científico a partir das suas noções provenientes do senso comum. De acordo com o prof. Marcos Silva, "o ruim é ficar só nessa experiência... Na condição de professores de história, e acompanhando nossos alunos, é preciso ir além”. (Silva, 2007, p. 78) Partir do que os/as alunos/as conhecem enquanto bagagem proveniente da experiência do cotidiano pode revelar-nos um caminho possível no ensino, em que o conteúdo não seja utilizado de forma descritiva, mas problematizado, de forma a possibilitar aos discentes compreenderem e intervirem na realidade social. 
Por último, atravessando todos esses eixos, encontram-se as habilidades a serem desenvolvidas pelos alunos das escolas. Quais habilidades deverão ser propostas para que os alunos as desenvolvam? Que capacidades pretende-se desenvolver com os/as alunos/as? Segundo os Parâmetros Curriculares Nacionais,

A apropriação de noções, métodos e temas próprios do conhecimento histórico, pelo saber histórico escolar, não significa que se pretende fazer do aluno um "pequeno historiador" e nem que ele deve ser capaz de escrever monografias. A intenção é que ele desenvolva a capacidade de observar, de extrair informações e de interpretar algumas características da realidade do seu entorno, de estabelecer algumas relações e confrontações entre informações atuais e históricas, de datar e localizar as suas ações e as de outras pessoas no tempo e no espaço e, em certa medida, poder relativizar questões específicas de sua época. (PARÂMETROS CURRICULARES NACIONAIS, 1997/1998, p. 40)

Habilidades para problematizar, comparar, pesquisar, levantar, criticar, analisar documentos imagéticos no ensino de história se contrapõem às aulas expositivas, cheias de descrições factuais, passividades e linguagens homogêneas. Mas o foco aqui passa a ser os alunos e não os professores. No lugar das aulas expositivas, a defesa das aulas dialogadas, problematizadas, trabalhadas a partir do conhecimento prévio dos alunos.

Essa perspectiva para a prática de ensino de História aponta-nos para a análise de documentos em sala de aula com alunos/as do ensino fundamental e médio, dentro das suas condições. O desenvolvimento da capacidade de analisar documentos em sala de aula como uma música, uma imagem, um enunciado encontra-se no âmbito das habilidades - o último eixo - a serem desenvolvidas pelos/as alunos/as, às quais professores/as e estagiários/as devem estar atentos. Segundo Janice Theodoro (2004, p. 54),

não podemos repetir modelos. Temos de retomar os documentos históricos, as narrativas coloniais e aprender a identificar as origens de diferentes abordagens. A repetição de uma determinada estrutura, sem que levemos em conta as especificidades históricas, pode negar a razão do próprio conhecimento histórico. Nesse sentido, identificar é um trabalho importante a ser desenvolvido pelo aluno.

Para Circe Bittencourt, a análise de documentos em sala de aula pode ser prática capaz de introduzir os alunos/as no pensamento histórico, na 
iniciação aos métodos de trabalho dos/as historiadores/es. Os documentos podem ser tanto escritos quanto iconográficos, memórias e etc. No caso de documentos iconográficos, os/as alunos/as poderiam ser capazes de observar um quadro renascentista e, com análise, identificar as características do renascimento, do humanismo, das formas de percepção do mundo presente no pensamento do homem da Idade Moderna. Poderiam situar a obra no seu tempo histórico.

A noção de tempo histórico é fundamental no ensino de história nas fases fundamentais e médias da escola. Por meio dessa noção, articulamos o texto/documento com o universo social e cultural que produz e por ele é produzido. Relacionamos as noções de passado/presente/futuro como possibilidade de questionar (ou não!) a definição tradicional de que a história serve para estudar o passado, compreender o presente e projetar o futuro. Evidenciar a dimensão qualitativa do tempo histórico, produtora de significados sociais, possibilita problematizar o conhecimento histórico, apreender conceitos e sobretudo, articular o passado e o presente.

Esses eixos são, portanto, constitutivos da experiência escolar, imbricados com a prática de estágio. Sugerimo-los para qualquer aluno/a estagiário/a que preze o encaminhamento de uma prática de ensino satisfatória e concatenado às novas perspectivas de ensino de história. Foi portanto com bases nessas propostas que encaminhei os estágios nas universidades anteriormente referidas.

Com certeza, os eixos não resolveram os problemas do estágio, até porque eles - os problemas - fogem ao nosso alcance. Por exemplo, os/as alunos/as estagiários/as não foram capazes de construir uma experiência sólida em ensino devido às poucas aulas que necessitavam ministrar (em torno de 5 a 10 aulas), visto que a formação de professores/as de história é uma carreira a ser construída ao longo de alguns anos. Outro problema foi a dificuldade em torno da intervenção nas escolas públicas da rede municipal e estadual por meio de projetos pedagógicos, assunto a ser abordado em outra ocasião. Devido aos muitos anos de sucateamento, o estágio supervisionado em história ainda está longe de poder contribuir para desestabilizar o quadro precário.

Muitas outras propostas e experiências foram construídas na prática de estágio. Tais acúmulos permitiram-me não somente ensinar a ensinar história, mas também aprender a ensinar. Possibilitaram-me ter controle sobre o meu discurso, sobre minhas concepções de história. Permitiramme visualizar junto aos/às alunos/as que, ensinar é aprender e aprender é ensinar. 
TEACH AND LEARN TEACHING HISTORY

AвSTRACT: In this present article, my objective was to describe my experiences as a Professor in Didactics, Practical History Teaching and also in Supervised Practice in History at the Federal University of Goiás. For such, I discoursed on the proposals on the History teaching in the last years, such as the distance between the university and the school, the knowledge production, the didactic book, the thematic axle and the use of different languages used in History teaching. At last, I pointed out four different axles that guide History Teaching, the study of possible problems, the historical concepts, the relation between the past and the present, and the student's skills to be developed.

KeY-Words: History, teaching, Didactic.

NOTAS

1 O Centro de Ensino e Pesquisa Aplicada à Educação ou Colégio de Aplicação (CEPAE/UFG) é uma escola pública, composta das séries iniciais do ensino fundamental até o $3^{\circ}$. Ano do ensino médio.

2 No dia 25 de março de 2007, o jornal O Popular estampou em sua capa a notícia “Educação em Goiás piorou em 10 anos". Segundo a reportagem, indicadores do MEC mostraram acentuada queda da qualidade do ensino público em Goiás. Em 2005, o resultado do ENEM indicou média abaixo do desempenho. A reprovação na rede estadual foi de $12 \%$, a evasão chegou a $14,3 \%$ no ensino médio e a $9,2 \%$ no fundamental, a terceira maior do Brasil. Segundo a notícia, as deficiências são atribuídas à falta de investimento. Ver: Jornal O Popular, Goiânia, 25 de março de 2007. No plano nacional, a revista Carta Capital, de 11 de abril de 2007, noticiou em suas primeiras reportagens que, na última década, o ensino público brasileiro piorou. Segundo a matéria, os resultados do Sistema Nacional de Avaliação da Educação Básica (SAEB) divulgados em fevereiro de 2007, "trouxe(ram) os piores índices de rendimento entre alunos da $8^{\mathrm{a}}$. série do ensino fundamental e da $3^{\text {a }}$. série do ensino médio desde 1995, ano em que a metodologia do exame foi alterada para que pudesse ser comparada aos resultados de anos posteriores (o exame existe desde 1990). Apenas alunos da $4^{\text {a }}$. série apresentaram uma pequena melhora, de três pontos, mas o desempenho ainda é inferior ao de dez anos atrás." PEROZIM, Ricardo Prado. Impávido Colosso. Revista Carta Capital. Política, Economia e Cultura. 11 de abril de 2007. Ano XIII, n. 439.

3 KARNAL, Leandro. História e Ensino: novas perspectivas. Palestra realizada durante o I Simpósio Internacional de História. Cultura e Identidades. Goiânia: Universidade Federal de Goiás, 2003. 
4 Esta representação, que desvalorizava o ensino frente à pesquisa, por mim observada quando escutei: "Mas você vai ministrar didática? Que desperdício!", comentou-me assustada uma professora. "Não é por nada não, mas a didática é uma disciplina muito chata!", confessou outra.

5 Sobre o assunto ver: CABRINI, Conceição e outras. O ensino de História/ Revisão Urgente. São Paulo: Brasiliense, 1986. FENELON, Déa R. A Formação do profissional de História e a realidade do ensino. In: Cadernos Cedes-Licenciatura. São Paulo: Cortez/Cedes, n. 8, 1983. NADAI, Elza. O ensino de História no Brasil: trajetória e perspectiva. Revista de História, n. 25/26. São Paulo, ANPUH, 1993, p. 143-162. NADAI, Elza. O ensino de História e a "Pedagogia do Cidadão" In: PINSKY, Jaime e outros (orgs.). O ensino de História e a criação do fato. 11. ed. São Paulo: Contexto, 2004. SILVA, Marcos. (org.) Repensando a história. Rio de Janeiro: Anpuh/Marco Zero, 1984.

6 Sobre as reflexões acerca do livro didático e seu uso em sala de aula ver: Fonseca, Selva. Livros Didáticos e Paradidáticos de História. In: FONSECA, Selva Guimarães. Didática e Prática de Ensino de História. 2. ed. São Paulo: Papirus, 2004, p. 49-58. Ver também BITTENCOURT, Circe. Livros Didáticos entre textos e imagens In: BITTENCOURT, Circe. (org) O saber histórico na sala de aula. 6. ed. São Paulo: Contexto, 2002. (Repensando a História). Em outro momento, Circe Bittencourt aprofunda suas reflexões sobre o uso do livro didático na parte 3 do livro: BITTENCOURT, Circe. Ensino de História: fundamentos e métodos. São Paulo: Cortez, 2004. (Coleção Docência em Formação).

7 A respeito da experiência dos professores como "saber", ver TARDIF, Maurice. Saberes Docentes \& Formação Profissional. 2. ed. Petrópolis: Vozes, 2002.

8 Sobre a relação entre livro didático e indústria cultural ver: FONSECA, Selva. Caminhos da História Ensinada. 7.ed. Campinas, SP: Papirus, 1993. (Coleção Magistério. Formação e Trabalho Pedagógico). Ver também: FONSECA, Selva Guimarães. Didática e Prática de Ensino de História. 2 ed. São Paulo: Papirus, 2004.

9 Sobre o assunto ver: FONSECA, Selva. Ensino de História: Diversificação de Abordagens. In: Revista Brasileira de História. Vol. 09, n. 19, Marco Zero, Anpuh, São Paulo, 1990.

10 BRASIL/SECRETARIA DA EDUCAÇÃO FUNDAMENTAL (1997/1998). Parâmetros Curriculares Nacionais. História e Geografia. Brasília: MEC/SEF.

11 Esta perspectiva de História alinha-se às propostas da História Cultural. Sobre o assunto ver: PESAVENTO, Sandra Jatahy. História \& História Cultural. Belo Horizonte: Autêntica, 2003. Ver também o capítulo 6 da obra: HUTCHEON, 
Linda. Poética do Pós-Modernismo - história, ficção, teoria. Tradução Ricardo Cruz. Rio de Janeiro: Imago, 1991.

12 Sobre algumas reflexões ou possibilidades de aplicação dessas novas linguagens Sobre o assunto ver a $2^{\text {a }}$. parte "Linguagem e Ensino" da obra: BITTENCOURT, Circe. (org) O saber histórico na sala de aula. 6. ed. São Paulo: Contexto, 2002. (Repensando a História). Ver também: RUIZ, Rafael. Literatura. Novas formas de abordar o ensino de História. In KARNAL, Leandro. (org). História na sala de aula: conceitos, práticas e propostas. 2. Ed. São Paulo: Contexto, 2004. Ver também a 3a. parte "Materiais Didático: concepções e usos" da obra: BITTENCOURT, Circe. Ensino de História: fundamentos e métodos. São Paulo: Cortez, 2004. (Coleção Docência em Formação). Ver também NAPOLITANO, Marcos. Como usar o cinema na sala de aula. 2. ed. São Paulo: Contexto, 2005.

13 Sobre o uso de documento em sala de aula, ver: BITTENCOURT, Circe Maria Fernandes. Ensino de História: fundamentos e métodos. São Paulo: Cortez, 2004. (Coleção docência em formação. Série Ensino Fundamental), Parte III, Capítulos 2 e 3.

14 Sobre os saberes existentes no trabalho em sala de aula ver: TARDIF, Maurice. Saberes Docentes \& Formação Profissional. 2. ed. Petrópolis: Vozes, 2002.

\section{REFERÊNCIAS}

BEZERRA, Holien G. Conceitos Básicos. Ensino de História: conteúdos e conceitos básicos. In: KARNAL, Leandro (org). História na sala de aula: conceitos, práticas e propostas. 2. ed. São Paulo: Contexto, 2004.

BITTENCOURT, Circe. (org) O saber histórico na sala de aula. 6. ed. São Paulo: Contexto, 2002. (Repensando a História).

BITTENCOURT, Circe. Ensino de História: fundamentos e métodos. São Paulo: Cortez, 2004. (Coleção Docência em Formação).

BITTENCOURT, Circe. Livros Didáticos entre textos e imagens In: BITTENCOURT, Circe. (org) O saber histórico na sala de aula. 6. ed. São Paulo: Contexto, 2002. (Repensando a História).

BRASIL/SECRETARIA DA EDUCAÇÃO FUNDAMENTAL (1997/1998). Parâmetros Curriculares Nacionais. História e Geografia. Brasília: MEC/SEF.

FONSECA, Selva Guimarães. Didática e Prática de Ensino de História. 2. ed. São Paulo: Papirus, 2004.

FONSECA, Selva. Caminhos da História Ensinada. 7. ed. Campinas: Papirus, 1993. (Coleção Magistério. Formação e Trabalho Pedagógico). 
FONSECA, Selva. Ensino de História: Diversificação de Abordagens. In: Revista Brasileira de História. Vol. 09, n. 19, Marco Zero, Anpuh, São Paulo, p. 197-208, set.89/fev. 1990.

FOUCAULT, Michel. Arqueologia do Saber (trad. Luiz Felipe Baeta Neves). 6. ed. Rio de Janeiro: Forense Universitária, 2000.

HUTCHEON, Linda. Poética do Pós-Modernismo - história, ficção, teoria. (trad. Ricardo Cruz). Rio de Janeiro: Imago, 1991.

JODELET, Denise. Representações Sociais: um domínio em expansão. In: JODELET, Denise (org). As Representações Sociais. Tradução Lílian Ulup. Rio de Janeiro: Editora da UERJ, 2001.

KARNAL, Leandro. (org). História na sala de aula: conceitos, práticas e propostas. 2. ed. São Paulo: Contexto, 2004.

KARNAL, Leandro. História e Ensino: novas perspectivas. Palestra realizada durante o I Simpósio Internacional de História. Cultura e Identidades. Goiânia: Universidade Federal de Goiás, 2003.

LIBÂNEO, José Carlos. Didática. São Paulo: Cortês, 1994.

NAPOLITANO, Marcos. Como usar o cinema na sala de aula. 2. ed. São Paulo: Contexto, 2005.

PESAVENTO, Sandra Jatahy. História \& História Cultural. Belo Horizonte: Autêntica, 2003.

SILVA, Marcos; FONSECA, Selva. Ensinar História no século XXI: em busca do tempo perdido. São Paulo: Papirus, 2007.

TARDIF, Maurice. Saberes Docentes \& Formação Profissional. 2. ed. Petrópolis: Vozes, 2002.

THEODORO, Janice. Transversalidade. A Transversalidade e a renovação do ensino de História. In: KARNAL, Leandro. (Org). História na sala de aula: conceitos, práticas e propostas. 2. ed. São Paulo: Contexto, 2004. 